\title{
The impacts of tropical agriculture on biodiversity: a meta-analysis
}

\author{
Joseph Oakley $^{1}$ and Jake Bicknell ${ }^{1}$ \\ ${ }^{1}$ University of Kent Durrell Institute of Conservation and Ecology
}

December 7, 2021

\begin{abstract}
Biodiversity underpins all food production and strengthens agricultural resilience to crop failure. However, agricultural expansion is the primary driver of biodiversity loss, particularly in the tropics where crop production is increasing and intensifying rapidly to meet a growing global food demand. It is therefore crucial to ask, how do different crops and crop production systems impact biodiversity? Here we show the increasing intensification of tropical agriculture since 1961, along with a sharp rise in harvested area. Using meta-analysis, we find that crop type, rotation time and agricultural intensity, are important determinants of biodiversity assemblages. Perennial tropical crops that are grown in shaded plantations or agroforests (e.g., banana and coffee) support higher alpha-diversity, while those cultivated in unshaded and often homogeneous plantations (e.g., maize, sugarcane, and oil palm) have impoverished biodiversity communities, particularly annual crops. These findings inform our understanding of changes in the ecological contribution of biodiversity to tropical agriculture.
\end{abstract}

\section{Hosted file}

Oakley and Bicknell Manuscript.pdf available at https://authorea.com/users/449922/articles/ 548379-the-impacts-of-tropical-agriculture-on-biodiversity-a-meta-analysis 